\title{
Gold Nanoparticles on Yttrium Modified Titania: Support Properties and Catalytic Activity
}

José J. Plata (1), Antonio M. Márquez (1), Javier Fdez. Sanz (1) ， Rafael Sánchez Avellaneda (2), Francisca Romero-Sarria (2), María Isabel Domínguez (2), Miguel Angel Centeno (2) and José Antonio Odriozola (2)

(1) Departamento de Química Física, Facultad de Química, Universidad de Sevilla, Sevilla, Spain

(2) Departamento de Quimica Inorgánica e Instituto de Ciencia de Materiales de Sevilla, Centro Mixto Universidad de Sevilla-CSIC, Avda. Américo Vespucio, 49, 41092 Sevilla, Spain

\begin{abstract}
A series of titanium oxide catalysts modified with yttrium has been prepared by sol-gel method and their structural properties have been studied. The incorporation of yttrium in the titania lattice favors the formation of oxygen vacancies while at low Y loadings the anatase structure is preserved. The catalytic activity of these solids for $\mathrm{CO}$ oxidation is found to be significantly dependent on their physical properties. In particular the amount of dopant controls the number of surface oxygen vacancies created as well as the gold particle size, which directly affects the catalytic activity. Also, a linear relationship between the catalytic activity and the band gap values, which depend on the $\mathrm{Y}$ loading, is observed. Density functional theory based calculations show that $\mathrm{Y}$ atoms are incorporated at the $\mathrm{TiO} 2$ surface at substitutional positions only, while the preferred oxygen vacancies arise by removing the bridge surface oxygen atoms. These $\mathrm{O}$ vacancies are the preferential adsorption sites for $\mathrm{Au}$ atoms and nanoparticles, acting as nucleation centers that favor the dispersion of the catalyst active phase over the support surface. In agreement with experiment, $\mathrm{Y}$ doping is found to decrease the band gap of the support due to a destabilization of the valence band of the oxide.
\end{abstract}

\section{Keywords}

$\mathrm{Au} / \mathrm{TiO} 2-$ anatase, Yttrium doping, CO-oxidation, Oxygen-vacancies, DFT

\section{Introduction}

The high activity shown by gold based catalysts in oxidation reactions has motivated an increasing in the number of works devoted to this subject in the last years [1-14]. The main parameters governing the processes catalyzed by gold nanoparticles (NPs) are: the size and shape, the oxidation state of the surface species, and the reducibility properties of the support. Although there is no agreement in the literature on which is the active gold species in the $\mathrm{CO}$ oxidation reaction [15-17], it is well established that small gold NPs $(2-3 \mathrm{~nm})$ deposited on a reducible support like $\mathrm{TiO} 2$ or $\mathrm{CeO} 2$ are more active than 
for instance when supported on $\mathrm{MgO}$ or $\mathrm{SiO} 2$ [18]. In a previous paper, we have shown that the creation of oxygen vacancies in $\mathrm{CeO} 2$, results in a decreasing of the average size of the gold particles deposed on it [19]. Other authors [20] explain this fact arguing that the support defects (vacancies) act as nucleation centers for the incoming gold, binding it strongly and hindering the agglomeration. Moreover, these authors conclude that gold is weakly adsorbed on a stoichiometric (free of defects) surface of titania, presenting a high mobility and making it possible the gold to sinter. Similar results have been reported from theoretical calculations, showing that the presence of vacancies on a $\mathrm{TiO} 2$ surface inhibits the formation of large gold particles [21].

A controversial point in the understanding of the $\mathrm{CO}$ oxidation mechanism concerns the charge state of the active gold NPs. For instance Minato et al. [22] proposed that the presence of $\mathrm{Au} \delta^{-}$species is necessary during the reaction because the oxygen is activated on them by charge transfer from gold NPs towards the $2 \pi^{*}$ levels of the $\mathrm{O} 2$ molecule. This provokes the weakening of the $\mathrm{O}-\mathrm{O}$ bond and the $\mathrm{CO}$ oxidation is favored. As a consequence of this electronic transfer and oxygen activation, the gold species are transformed into $\mathrm{Au} \delta+$ ones. A mechanism involving a similar charge transfer in a peroxo-like species has been theoretically substantiated on the basis of density functional calculations [23]. The coexistence of gold species in different oxidation states during the $\mathrm{CO}$ oxidation has been interpreted by Wörz et al. [24] suggesting that $\mathrm{CO}$ is weakly adsorbed on the $\mathrm{Au} \delta^{-}$- species (on a vacant site) and therefore, its negative charge is maintained. In contrast, $\mathrm{CO}$ adsorption on $\mathrm{Au}$ on a stoichiometric surface induces charge transfer from the metal particle to the support, generating a stable $\mathrm{Au} \delta+-\mathrm{CO}$ species.

The stability, reducibility, mechanical and chemical properties of titania makes it a common choice for support in both heterogeneous catalysis and photocatalysis, and, as aforementioned, the activity relies on the presence of surface oxygen vacancies, i.e. the presence of Ti3+ surface species. A straightforward possibility to foster the activity is by doping with a transition metal with a different oxidation number. This practice is commonly done as well in photocatalysis, where the introduction of metals in the titania lattice induces a modification in the band structure. An adequate choice of the metal may drive to a situation in which, the introduced dopant states are located in the band gap, thus changing their absorption properties. These localized states may come not only from the dopant $d$ orbitals but also from the vacancies that the charge balance requires ( $3 \mathrm{~d}$ states of $\mathrm{Ti} 3+$ ). This is for instance the case of $\mathrm{Cr} 3+/$ titania doping, where a new strong absorption is observed in the visible region [25].

Doping titania with a trivalent cation like $\mathrm{Y} 3+$, naturally gives rise to structures with oxygen vacancies. Actually, for a given amount of yttrium the most stable phase of the mixed metal oxide is that of pyrochlore, Ti2Y2O7, that may be considered as a fluoritetype structure with one eighth of the anions missing, that means, with oxygen vacancies [26]. The structure and properties of supports based on Y doped titania, as well as the catalytic activity of Au NPs deposited on such supports has been the subject of a systematic and extensive recent work [27]. In the present paper we report theoretical 
and experimental results on the structure of $\mathrm{Y}$ doped titania that correspond to different low Y loadings that preserve the anatase structure. Once the support has been analyzed, the structure of deposited gold NPs is considered. The experimental characterization is based on UV-VIS and XRD data while the theoretical analysis is carried out using density functional theory, DFT, calculations. The paper is arranged as follows: Sects. 2 and 3 deal with the experimental and theoretical techniques and methods used, respectively. The results are reported and discussed in Sect. 4, starting by some catalytic results, characterization data and, finally, the theoretical analysis.

\section{Characterization}

\subsection{Supports}

The synthesis of the supports has been carried out following a sol-gel method. Titanium tert-butoxyde (Sigma, 97\%) and yttrium nitrate (Y2(NO3)3.6H2O 99.9\% Alfa-Aesar) were used as metallic precursors. The adequate amounts of each reactive were dissolved in $125 \mathrm{~mL}$ of 1-butanol and stirred for $24 \mathrm{~h}$. The resulting homogeneous solution was maintained under reflux at $134{ }^{\circ} \mathrm{C}$ for $4 \mathrm{~h}$ and then cooled to room temperature. After that, $7.45 \mathrm{~mL}$ of a $\mathrm{H} 2 \mathrm{O} / \mathrm{NH} 3$ (28.5/1 ratio) solution was added droply. After $24 \mathrm{~h}$, a gel was obtained. It was centrifuged at $15000 \mathrm{rpm}$ for $15 \mathrm{~min}$ and the remaining solvent eliminated by Soxhlet solid-liquid extraction using ethanol $\left(48 \mathrm{~h}, 96^{\circ} \mathrm{C}\right)$. The obtained product was dried at $100{ }^{\circ} \mathrm{C}$ for $24 \mathrm{~h}$ and finally, calcined at $300{ }^{\circ} \mathrm{C}$ during $2 \mathrm{~h}$. The final solid will be denoted as TiYx, being $\mathrm{x}$ the weight percentage of yttrium.

\subsection{Gold Catalysts}

The gold containing catalysts were prepared by deposition-precipitation. The adequate amount of $\mathrm{HAuCl} 43 \mathrm{H} 2 \mathrm{O}$ (Alfa, $99.99 \%$ pure) to obtain $1 \% \mathrm{wt}$ of gold in the support, was dissolved in $100 \mathrm{~mL}$ of deionized water and the $\mathrm{pH}$ of the solution adjusted to 7.0 by addition of $\mathrm{NaOH} 0.1 \mathrm{M}$ in an automatic system of measurement and titration (CRISON pH-Burette 24). The solution was heated to $70{ }^{\circ} \mathrm{C}$ and then, the support was added and kept under continuous stirring for $1 \mathrm{~h}$. The samples obtained were washed several times (until the disappearance of $\mathrm{Cl}-$ and $\mathrm{Na}+$ ions), then dried during $24 \mathrm{~h}$ at $100{ }^{\circ} \mathrm{C}$ and finally calcined $2 \mathrm{~h}$ at $300{ }^{\circ} \mathrm{C}$.

\subsection{Characterization Techniques}

BET specific surface area was measured by nitrogen adsorption measurements at liquid nitrogen temperature in a Micromeritics ASAP 2010 apparatus. Before analysis, the samples were degassed $2 \mathrm{~h}$ at $150{ }^{\circ} \mathrm{C}$ in vacuum. The isoeletric point (IEP) of the support was determined by measuring (Malven Zetamaster) electrophoretic mobilities of aqueous dispersions as a function of $\mathrm{pH}$, at constant ionic strength (10-2 mol dm-3 $\mathrm{NaCl}$ ). The $\mathrm{pH}$ was varied by adding $\mathrm{HCl}$ or $\mathrm{NaOH}$, as needed. X-Ray diffraction (XRD) patterns were recorded using a Siemens Kristalloflex D-501 diffractometer working with $\mathrm{Cu}-\mathrm{K} \alpha$ radiation $(\lambda=1.5404 \AA)$ in continuous scan mode over a $2 \theta$-range of $20-80^{\circ}$ using a step size of $0.05^{\circ}$ and a step time of $1.0 \mathrm{~s}$. The mean gold crystallite 
sizes were estimated using the Scherrer equation. For that purpose, XRD diffractograms of gold samples were recorded from $2 \theta 35-45^{\circ}$ using a step size of $0.02^{\circ}$ and a step time of $4.0 \mathrm{~s}$. A peak broadening due to the instrumental broadening of $2 \theta=0.11^{\circ}$ was taken into account.

Chemical composition of catalyst was determined by X-ray fluorescence (XRF) with a Siemens SRS 3000 sequential spectrophotometer equipped with a rhodium tube. XRF measurements were performed onto pressed pellets (sample included 10\% wt of wax). Diffuse Reflectance UV-VIS spectra of the solids diluted in BaSO4 were recorded at room temperature on a Varian Cary 100 conc spectrometer equipped with an integrating sphere and using BaSO4 as reference.

\subsection{Activity Measurements}

The catalytic tests were carried out in a conventional continuous flow U-shape glass reactor working at atmospheric pressure. The sample $(80 \mathrm{mg})$ was placed between two plugs of glass wool. A thermocouple in contact with the sample assures the right measure of temperature. The feed mixtures were prepared using mass flow controllers (Bronkhorst). The reaction was followed by mass spectrometry, using a Balzers Thermostar benchtop mass spectrometer controlled by the software Balzers Quadstar 422 with capabilities for quantitative analysis. The light-off curves of $\mathrm{CO}$ oxidation $\left(300{ }^{\circ} \mathrm{C}, 5{ }^{\circ} \mathrm{C} / \mathrm{min}\right.$ ) were obtained with a mixture of 3.4\% $\mathrm{CO}$ (Air Liquide, $99.997 \%$ pure, <3 ppm H2O) and 21\% O2 (Air Liquide, 99.999\% pure, <3 ppm H2O) balanced by $\mathrm{He}$ (Air Liquide, $99.999 \%$ pure, $<3 \mathrm{ppm} \mathrm{H} 2 \mathrm{O}$ ) at a total flow rate of $42 \mathrm{~mL} / \mathrm{min}$. Empty reactor shows no activity under such conditions. The catalysts were pre-activated in situ for $1 \mathrm{~h}$ at $300{ }^{\circ} \mathrm{C}$ with a mixture of $21 \% \mathrm{O} 2$ in $\mathrm{He}$ at a flow of $30 \mathrm{~mL} / \mathrm{min}$ and then stabilized at room temperature before the light-off curve started.

\section{Computational Details}

To model the extended nature of these surfaces, periodic three-dimensional DFT calculations were carried out using the VASP 4.6 code [28-30] with the projector augmented wave (PAW) method [31, 32]. In these calculations, the energy was obtained using the generalized gradient approximation (GGA) implementation of DFT proposed by Perdew et al. [33] and the electronic states were expanded using plane wave basis set with a cutoff of $400 \mathrm{eV}$. A spin polarized formalism has been used when we were dealing with gold clusters with odd number of atoms. Forces on the ions were calculated through the Hellmann-Feyman theorem, including the Harris-Foulkes correction to forces [34]. This calculation of the force allows a geometry optimization using the conjugated gradient scheme. Iterative relaxation of the atomic positions was stopped when the forces on the atoms were less than $0.05 \mathrm{eV} / \mathrm{A}$. Experimental and theoretical studies have shown that the (101) plane is the most stable low index surface of anatase $\mathrm{TiO} 2[35,36]$. It is also known that surface properties converge faster with the number of $\mathrm{TiO} 2$ layers in the model in anatase than in rutile and slab models with four $\mathrm{TiO} 2$ layers adequately reproduce experimental data as surface energies [36]. For the initial analysis of the preferential substitution of $\mathrm{Ti}$ atoms by $\mathrm{Y}$ atoms a $2 \times 2$ four-layer thick 
supercell was selected. For Au clusters deposition, and to explore higher Y loadings, a larger $3 \times 3$ two-layer thick supercell was adopted (see Fig. 1). In all cases, the supercell includes a vacuum of $14 \AA$. The calculations with the $2 \times 2 \times 4$ supercells were performed using a $2 \times 2 \times 1$ Monkhorst-Pack set of k-points [37] while those corresponding to the larger, $3 \times 3 \times 2$ supercell were sampled at the $\Gamma$ point of the Brillouin zone. To analyze the charge transfer upon adsorption a Bader type analysis was performed [38-40].

\section{Results and Discussion}

\subsection{Catalytic Activity}

Figure 2 shows the $\mathrm{CO}$ conversion as a function of the temperature for the studied catalysts. It is observed that the non-doped solid presents around $90 \%$ conversion at 300 ${ }^{\circ} \mathrm{C}$. For the doped solids, total conversion of $\mathrm{CO}$ is achieved at much lower temperatures $\left(125^{\circ} \mathrm{C}\right.$ for TiY6 and $100{ }^{\circ} \mathrm{C}$ for TiY11). For the sample with the highest $\mathrm{Y}$ loading, the activity measured at room temperature is $\approx 20 \%$. These results show that incorporating yttrium into the $\mathrm{TiO} 2$ structure has a positive effect on the catalytic properties either by modifying the surface physical properties, including the $\mathrm{O}$-vacancy concentration, or by influencing the gold particle size and hence the reactivity.

\subsection{Experimental}

\subsubsection{Supports: Physical Properties (XRF, SBET, IEP)}

The physical properties of the considered solids are reported in Table 1. Starting with the amount of Y doping, one can see that in general, the higher the amount of yttrium used in the preparation, the higher the amount incorporated into the solid. At low yttrium contents, both values, the nominal and the real, agree. However, at high loadings, the yttrium quantity in the support reaches a maximal value (about $24 \% \mathrm{wt}$ ), suggesting the existence of some limitations, probably of structural type, to the incorporation of yttrium into the lattice (see also Fig. 3). Notice that as the ionic radius of $\mathrm{Y} 3+(0.93 \AA)$ is significantly larger than that of Ti4+ $(0.68 \AA)$, [41] the insertion of high quantities of yttrium in the titania lattice is necessarily limited. This result is in agreement with the $\mathrm{Y} 2 \mathrm{O} 3-\mathrm{TiO} 2$ phase diagram [42] showing a eutectic point for $10 \%$ Y2O3 at $1580{ }^{\circ} \mathrm{C}$. However, no phase associated to pure yttrium oxide has been detected by XRD in the solids calcined in the $300-1200{ }^{\circ} \mathrm{C}$ range.

The textural properties of the solids were obtained from N2 adsorption-desorption isotherms. The isotherms correspond to typical mesoporous materials with complex pore structures made up from interconnected networks of pores of different size and shape (not shown). The specific surface area of the solid (Table 1) reflects the effect of yttrium in hindering the sintering of the titania particles upon calcination, gold deposition hardly modify the textural properties of the supports.

The isoelectric points (IEP) of the prepared supports are shown in Table 1. This value indicates both the $\mathrm{pH}$ at which an immersed solid oxide surface has zero net charge and 
the $\mathrm{pH}$ resulting in electrically equivalent concentrations of positive and negative complexes [43]. The IEP value of the titanium oxide support is 4.73 . This value agrees with than reported for a non-hydrated synthetic titania [43]. The modification of the acid-base properties of the solids from yttrium contents correlates fairly well with gold particle size.

\subsubsection{UV-VIS Spectra}

In general, titania doping with a transition metal induces the appearance of a "new" band gap (called secondary band gap) with lower values than the corresponding to the pure oxide (called main band gap) [44]. Moreover, it has been proposed that the doping in the titanium oxide structure favors oxygen vacancies [45]. These oxygen vacancies play an important role in oxidation reactions since oxidative species, such as superoxide and peroxide ones, are formed from them by reaction with molecular oxygen present in the reactive flow [46].

The UV-VIS spectra of the supports are shown in Fig. 4. We observe a "tail" of absorption at low energies for the supports with yttrium contents between 0 and $11 \%$ wt, which has been attributed to the presence of dopants [16, 17]. The band gap value was calculated by plotting the square root of the Kubelka-Munk function multiplied by the photon energy $(\mathrm{KM} \times \mathrm{h} v) 1 / 2$ versus the photon energy $(\mathrm{eV})$ and extrapolating the linear part of the rising curve to zero as reported in Table $2[13,47]$.

In the solid without yttrium (TiY0) the observed "tail" of absorption is due to the presence of Ti3+ [48], suggesting that, by itself, the synthesis method induces the creation of vacancies. The secondary band gap in this support is $1.94 \mathrm{eV}$, while its main band gap, $3.13 \mathrm{eV}$, is close to that reported for pure anatase $(3.2 \mathrm{eV})$. For the solids with yttrium contents of 6 and $11 \% \mathrm{wt}$, the secondary band gap values are 2.27 and $2.34 \mathrm{eV}$ respectively; while their main band gaps (3.05 and $3.08 \mathrm{eV}$ ) are slightly lower than that of TiY0. The decreasing of the main band gap has been attributed to the band structure modification of titania by the introduction of dopants [48]. The secondary band gap is associated to the defect structure. The activity measured through the T50 increases on increasing the yttrium content (see Fig. 5) and therefore on modifying the defect structure. A similar correlation between catalytic activity and band gap of the catalysts was previously observed for $\mathrm{Au} / \mathrm{CeO} 2-\mathrm{A} 12 \mathrm{O} 3$ catalysts [13].

\subsubsection{XRD}

All the supports calcined at $300{ }^{\circ} \mathrm{C}$ are amorphous solids, which avoids extracting any information about their structure. To obtain some clues about it, the samples were calcined at higher temperatures (up to $1200{ }^{\circ} \mathrm{C}$ ), collecting a diffractogram each $50{ }^{\circ} \mathrm{C}$. The structural differences observed between supports treated at the same temperature reflect the differences in the local compositions and permit us to observe if some phase segregation is produced. As an example, Fig. 6 shows the diffractograms corresponding to TiY11 and TiY13 samples calcined at $950{ }^{\circ} \mathrm{C}$. These two supports have been chosen because in their range of composition (11-13\% wt yttrium), the secondary band gap 
strongly decreases while the main band gap raises up to that of pure anatase. The XRD patterns of both samples are markedly different. In both cases, although with different crystallinity and ratio, peaks due to anatase and rutile are detected. Besides these, diffraction lines characteristic of a stoichiometric pyrochlore (Ti2Y2O7) and/or a nonstoichiometric pyrochlore (TiYO2.085) structures are observed. The appearance of these last two structures (both containing defects) suggests the success of the insertion of yttrium in the titania network. On the other hand, a shift in the $2 \theta$ position of the rutile and anatase peaks in both samples is observed, indicating a different modification of each support, related, probably, with the yttrium content.

From the XRD study of the supports calcined at different temperatures (results not completely shown), the following observations have been extracted: (1) the anatase to rutile transformation is observed at about $900{ }^{\circ} \mathrm{C}$, higher than that of pure phase $(500$ $\left.{ }^{\circ} \mathrm{C}\right)[49]$, and, both, the anatase and/or rutile phases, are present in all the range of temperatures studied. This high temperature of anatase to rutile change of phase is provoked by the interaction of the titanium oxide with the dopant, as previously established [50]; (2) pyrochlore structures (stoichiometric and non-stoichiometric) are always detected and; (3) no phase associated to yttrium oxide or any other segregated yttrium structure, has been observed. These three observations confirm that yttrium has been incorporated into $\mathrm{TiO} 2$. However, in all cases, part of the titanium oxide is free of yttrium, as deduced from the joint detection of anatase and/or rutile, phases together with pyrochlore ones. This fact may be understood considering that, as aforementioned, the ionic radius of yttrium is significantly larger than that of titanium, making difficult the introduction of yttrium in the bulk of the titanium oxide. These observations suggest that yttrium interacts with the titanium oxide only on the surface, which could explain why no more than $24 \%$ wt yttrium may be introduced in the titania network, as observed by the XRF analysis.

\subsection{Theoretical Calculations}

\subsubsection{Geometries and Electronic Structure}

To setup the model calculations, and in agreement with the XRD and XRF data, we assume that $\mathrm{Y}$ atoms are incorporated into the $\mathrm{TiO} 2$ network in substitutional positions, as the large atomic radius of $\mathrm{Y}$ will make an interstitial incorporation very unlikely. In a first step we considered all the different possible substitutional sites in a $2 \times 2 \mathrm{TiO} 2$ supercell four-layer thick, exposing the (101) face. In such a model a single Y/Ti substitution represent a $\mathrm{Y}$ percentage of $6.25 \%$, and allows us to distinguish four different sites: two surface sites (penta- and hexa-coordinated, hereafter labeled as Ti5c and Ti6c) and two subsurface sites. To keep the formal oxidation degree of the system a surface anion has been replaced by a $\mathrm{OH}^{-}$group. The most favorable structure corresponds to the substitution at the Ti5c surface site. Substitution of surface Ti6c atoms is only moderately unfavorable $(0.3 \mathrm{eV})$, while substitutions at subsurface sites are very unlikely, as they are less stable by $0.8-0.9 \mathrm{eV}$. These results clearly demonstrate the preference of the $\mathrm{Y}$ atoms for surface substitutional sites and can be 
rationalized by the size differences between the two cations. Indeed, the larger size of the $\mathrm{Y}$ atoms requires a noticeable distortion of the $\mathrm{TiO} 2$ network that is much harder at subsurface or bulk positions.

Having established the preference of $\mathrm{Y}$ atoms for surface substitutional sites, we have now to increase the $\mathrm{Y}$ loading in our models to progressively approach to the experimental range of $\mathrm{Y}$ content and to understand the observed experimental trends. To this end, we will progressively substitute a pair of surface Ti atoms by $\mathrm{Y}$ atoms into a 3 $\times 3$ supercell model of the TiO2 (101) surface. To keep the formal oxidation states of the ions in this case, an O-vacancy is created each two Y/Ti atoms substitution. Taking into account all different ways of surface Y/Ti substitution and the relative position of the generated $\mathrm{O}$ vacant result in 39 different arrangements that have to be computed to rationalize the preferred distribution of $\mathrm{Y}$ atoms and $\mathrm{O}$ vacancies in the $\mathrm{TiO} 2$ (101) surface. The results show (see Supplementary Information) that at this level of Ydoping the most stable arrangements correspond, as expected, to having the two $\mathrm{Y}$ atoms occupying Ti5c sites but not in close contact each other. There are also arrangements where one $\mathrm{Y}$ atom occupies a surface Ti5c site and the second $\mathrm{Y}$ atoms a Ti6c site that is only modestly less stable (less than $0.4 \mathrm{eV}$ ). In all cases, the O-vacancy is more favorably created at the surface bridge sites, O2s. These findings can be rationalized by the larger average $\mathrm{Y}-\mathrm{O}$ bond distance $(2.26 \AA$ in $\mathrm{Y} 2 \mathrm{O} 3)$ compared to that of Ti-O (1.95 $\AA$ ). Indeed, when the $\mathrm{Y}$ atoms enter into substitutional sites at the $\mathrm{TiO} 2$ surface, the local geometry must strongly relax to accommodate the $\mathrm{Y}$ atom. When the O-vacancy is created in a nearby $\mathrm{O} 2 \mathrm{~s}$ site the $\mathrm{Y}$ atom is able to slightly displace away from the surface and the resulting local geometries show $\mathrm{Y}-\mathrm{O}$ distances similar to those of the $\mathrm{Y} 2 \mathrm{O} 3$.

To simulate yttrium loadings comparable to the experimentally prepared catalysts, up to six surface $\mathrm{Ti}$ atoms have been substituted by $\mathrm{Y}$ in the $3 \times 3$ model already mentioned. This represents a $17 \%$ of $\mathrm{Y}$ content in the model that is similar to those experimental catalysts having the maximum activity. Relying on the clear tendency of $\mathrm{Y}$ to be at the surface, only models where $\mathrm{Y}$ atoms are at surface Ti5c sites or with half of the $\mathrm{Y}$ atoms occupying Ti5c and the other half Ti6c sites have been considered. In all cases three $\mathrm{O} 2 \mathrm{~s}$ vacancies have been also created. The relative energies of the configurations computed are reported in Table 3. At this doping the most stable distribution of Y atoms on the TiO2 surface results in the formation of "Y2O3" dimers at the surface, with one $\mathrm{Y}$ atom occupying a Ti5c site and the second one in a nearby Ti6c site (see Fig. 7). The rationale for this behavior is that when the $\mathrm{Y}$ content increases, the arrangement of $\mathrm{Y}$ atoms at neighboring Ti5c is energetically unfavorable (as was previously discussed). Instead, the two $\mathrm{Y}$ atoms prefer to occupy neighboring Ti5c and Ti6c sites, with a Y-Y distance similar to that found in Y2O3. Moreover, these dimers are in turn also ordered on the $\mathrm{TiO} 2$ surface, generating an extended structure that seems to stabilize the whole system. These associations (see Fig. 7) can be related to coherent-incoherent precipitations [51] of $\mathrm{Y} 2 \mathrm{O} 3$ into the $\mathrm{TiO} 2$ surface matrix. 
An analysis of the relative stability of the different sites and loadings allows us for a rational of the limitations in the incorporation of $\mathrm{Y}$ into the solid experimentally observed. At low Y content in the precursor, the $\mathrm{Y}$ atoms will preferentially substitute surface Ti5c atoms and $\mathrm{O} 2 \mathrm{~s}$ vacancies will be generated in nearby sites. At higher loadings, a limit situation is reached, with the formation of the extended structures of yttrium dimers shown in Fig. 7. From this point, further incorporation of Y in the solid requires a surface reconstruction that can be associated to the observation of diffraction lines characteristic of pyrochlore structures in the XRD diffractograms.

An additional aspect that is worth commenting is related with the energetics of the oxygen vacancy formation. In general, the involved energies are large whatever the phase, rutile or anatase is considered [52, 53]. In particular, using the $3 \times 3$ model we estimate this energy to be $4.54 \mathrm{eV}$, in agreement with the value reported by Vittadini et al. [54]. However, removing oxygen atoms from this model after Y-doping turns to be an exothermic process, and actually even the third removal, which is the one that gives the correct stoichiometry, releases $0.08 \mathrm{eV}$. This relative stabilization of the titania $\mathrm{O}-$ vacancy that results from the interaction vacancy-dopant has already been reported in several cases involving both rutile [20, 55, 56] and anatase [57]. Moreover, it is worth mentioning the relationship between the easiness in the O-vacancy formation and the higher catalytic activity of the Y-doped titania, which is in agreement with recent work of Corma et al. [58] for the Fe-doped anatase.

Several studies available in the literature have related the introduction of dopant elements into the titania structure with a reduction in the band gap of the resulting material with respect to that of the undoped titania [59, 60]. To understand the modifications induced in the electronic structure by the presence of the dopant element and to be able to establish comparisons with the experimental UV-VIS data, the band structure of the models has been computed. In Fig. 8 the band structure for the models with $0 \%$ (undoped anatase), 6\% (two Y/Ti substitutions), and 16\% (six Y/Ti substitutions) are presented with the two most important indirect transitions shown. The band gap of the material has been estimated from the $\mathrm{D} \rightarrow \Gamma$ transition, and plotted in Fig. 9 along with the experimental band gaps obtained from the UV-VIS spectra. The agreement between the theoretical and the experimental trends is quite reasonable, taking into account the well-known trend of the GGA functionals to produce band gaps lower than the experimental values [61-63]. Further analysis of the band gap structure shows that there are no new states in the anatase band gap introduced by the dopant element and that the band gap narrowing is a result of a destabilization of the valence band of the oxide (mainly composed of $\mathrm{O} 2 \mathrm{p}$ levels) that pushes this band towards higher energies.

\subsubsection{Deposition of Gold Nanoparticles}

Let us now consider the interaction between gold nanoclusters and the support surface. To be able to establish comparisons, four different surface models have been developed. First clean undoped and Y-doped anatase and secondly, to account for the experimental 
working conditions, the presence of water has been modeled by adding hydroxyl groups and hydrogen atoms to these two surfaces.

We began our study by examining the adsorption of a single gold atom in the above described model surfaces. On each surface model, different adsorption sites have been tested and the bonding energies of the most stable configuration are presented in Table 4. These results show that, at low gold coverage, hydroxylation of the undoped surface improves the interaction between the gold atom and the surface increasing the binding energy from $-0.46 \mathrm{eV}$ on the clean surface to $-0.54 \mathrm{eV}$ on the hydroxylated surface. In both cases the preferred adsorption site is the same, a bridge site between two O2anions. Doping the surface, on the other hand, modifies the preferred adsorption site that is now the O-vacancy site, and results in a much larger adsorption energy $(-0.81$ $\mathrm{eV}$ ) for the gold atom. Considering now gold atom adsorption on a hydroxylated doped surface two possibilities arise: either the hydroxyl or the gold atom can occupy the Ovacancy site. In contrast with the increase in gold adsorption energy found on the undoped surface, hydroxylation of the doped surface reduces the strength of the goldsurface interaction. The computed binding energy is $-0.47 \mathrm{eV}$ when the gold atom sits on the O-vacancy and $-0.42 \mathrm{eV}$ when the hydroxyl fills the vacancy. Metal NPs dispersed at oxide support surfaces generally experiment sintering processes (form larger clusters) under reaction conditions. This results in a loss of catalyst activity due to the recognized correlation between catalyst activity and metal particle size [64]. On the undoped model surfaces it is found that the differences in gold atom adsorption energies are small between different sites $(-0.46$ to $-0.29 \mathrm{eV}$ on the dehydrated surface and -0.54 to $-0.38 \mathrm{eV}$ on the hydroxylated surface). We can, then, presume a high mobility for the gold atom in these surfaces and as result gold nanoclusters may easily diffuse and sinter in these surfaces. In contrast, on the doped-dehydrated surface, it is found that there is a larger difference in the binding energy of the gold atom at the vacancy or at nearby sites $(-0.81$ to $-0.64 \mathrm{eV})$ with respect to other sites at the surface $(-0.49$ to $-0.37 \mathrm{eV}$ ). This means that the vacancies will play a double role. First they favor the dispersion of the metal NPs over the surface as the number of vacancies increases with yttrium loading and secondly they will act as nucleation sites that will strongly anchor those metal nanoclusters, reducing the sintering processes. However, in the presence of surface hydroxyls the energy differences between the different adsorption sites is reduced $(-0.47$ to $-0.42 \mathrm{eV}$ at the O-vacancy or at nearby sites against -0.31 to -0.27 $\mathrm{eV}$ when the hydroxyl fills the O-vacancy). This means that surface hydroxylation will increase the mobility of gold over the surface, as result of the competition between $\mathrm{Au}$ and $\mathrm{OH}$ for the $\mathrm{O}$-vacancy site.

Starting from the most favorable adsorption sites for isolated gold atoms, the adsorption of Au4 clusters has also been examined. The computed binding energies, also summarized in Table 4, show a large difference between undoped and doped surfaces. For the Y-doped case, the Au4-surface interaction is enhanced with respect to the undoped surfaces. This can be appreciated both in the computed interaction energies displayed in Table 4 as well as in the adsorbed nanoclusters geometries (see Supporting 
Information). While at the undoped surfaces the nanoclusters display a threedimensional arrangement, with only one or two gold atoms interacting with the surface, at the doped surfaces, the gold nanoclusters seems to adopt a two-dimensional shape, increasing the number of gold atoms that directly interact with the support.

Besides acting as a structural promoter, facilitating the dispersion of gold nanoparticles over the surface and hindering their sintering under reaction conditions, the support also takes an active role by influencing the electronic structure of the deposited metal NPs [65]. To elucidate the effect of the support on the electronic properties of the Au4 clusters, the total density of states (DOS) and gold projected density of states (PDOS) of the Au4-support catalysts models have been examined. As shown in Fig. 10 the overlap between the valence band of the support and the electronic levels of the gold nanocluster is improved by Y-doping, as result of a shift of the support energy levels towards higher energies. It is worth mentioning here that when the energy levels of deposited gold nanoclusters are close to the $\mathrm{O} 2 \mathrm{p}$ band a higher catalytic activity with respect to the $\mathrm{CO}$ oxidation is obtained [13].

The effect of the support on the electronic properties of the metal NPs can also be probed by analyzing the charge transfer at the interface. To this end, Bader charges for increasing size gold nanoclusters, Aun $(n=1-4)$, have been determined (Table 5). The calculated charges show a different behavior for Y-doped surfaces against undoped ones. While for undoped surfaces the support oxidizes the Aun nanocluster, in doped surfaces there is a charge transfer from the support towards the metal cluster.

\section{Conclusions}

The strong influence of the support on the catalytic activity of gold-based catalysts in the $\mathrm{CO}$ oxidation reaction has been evidenced. The incorporation of yttrium into the titania lattice, that is accompanied by creation of oxygen vacancies, favors the conversion of $\mathrm{CO}$ at low temperatures. In order to clarify this point the catalysts have been characterized and interesting relationships between catalytic activity and physical properties have been established. The most important are: (a) the quantity of dopant introduced into the titania controls the number of surface oxygen vacancies created and the gold particle size, directly influencing the catalytic activity; and (b) the band gap is also modified by Y-doping, existing a linear relationship between the catalytic activity and the band gap values found for the studied solids.

A theoretical analysis based on density functional theory calculations allows us to interpret the main experimental findings. The relative energies show that $\mathrm{Y}$ atoms are almost exclusively incorporated into the titania at substitutional surface sites. Only a limited amount of surface $\mathrm{Ti}$ atoms can be substituted, explaining the restrictions experimentally found to the incorporation of the dopant into the titania support. The oxygen vacancies generated to balance the charge (bridge surface oxygen atoms) are found to be preferential adsorption sites for Au atoms and NPs, acting as nucleation centers that favor the dispersion of the catalyst active phase over the support surface. The interaction between the gold NP and the support is analyzed by examining the 
electronic structure of the system. It is found that, as result of Y incorporation into the titania surface, the valence band of the support, composed mainly of O $2 p$ energy levels, is shifted towards higher energies. A straightforward consequence is that the band gap of the support is reduced, in agreement with experimental UV-VIS spectra. A further consequence is that the overlap with the electronic levels of the gold NPs is improved, enhancing the interaction with the support.

\section{Acknowledgements}

This work was funded by the Ministerio de Ciencia e Innovación, Spain, (grants ENE2009-14522-C05-01, MAT2008-04918 and CSD-00023, co-financed by FEDER from European Union), and the Junta de Andalucía (project P08-FQM-03661). RomeroSarria thanks the Spanish MEC for her contract (Ramón y Cajal Programme). The Red Española de Supercomputación (RES-BSC) provided part of the computer time. 


\section{References}

1. Haruta M (1997) Catal Today 36:153

2. Meyer R, Lemire C, Shaikuthdinov SK, Freund HJ (2004) Gold Bull 37:72

3. Nijhuis TA, Weckhuysen BM (2006) Catal Today 117:84

4. Thompson DT (2003) Appl Catal A 243:201

5. Abad A, Almela C, Corma A, Garcìa H (2006) Tetrahedron 62:6666

6. Jacobs G, Ricote S, Patterson PM, Graham UM, Dozier A, Khalid S, Rhodus E, Davis BH (2005) Appl Catal A 292:229

7. Kim CH, Thompson LT (2005) J Catal 230:66

8. Wang X, Rodrìguez JA, Hanson JC (2005) J Chem Phys 123:221101

9. Silberova BAA, Mul G, Makkee M, Moulijn JA (2006) J Catal 243:171

10. Bond GC, Thompson DT (1999) Catal Rev Sci Eng 41:319

11. Bond GC, Louis C, Thompson DT (2006) Cataysis by gold. Imperial College, London

12. Centeno MA, Paulis M, Montes M, Odriozola JA (2002) Appl Catal A 234:65

13. Centeno M, Portales C, Carrizosa I, Odriozola JA (2005) Catal Lett 102:289

14. Carriazo JG, Martínez LM, Odriozola JA, Moreno S, Molina R, Centeno MA (2007) Appl Catal B 72:157

15. Minicó S, Scire S, Crisafulli C, Visco AM, Galvagno S (1997) Catal Lett 47:273

16. Pillai UR, Deevi S (2006) Appl Catal A 229:266

17. Arena F, Famulari P, Trunfio G, Bonura G, Frusteri F, Spadaro L (2006) Appl Catal B 66(1-2):81

18. Schubert M, Hackenberg S, van Veen AC, Muhler M, Plzak V, Behm RJ (2001) J Catal 197:113

19. Romero-Sarria F, Martínez LM, Centeno MA, Odriozola JA (2007) J Phys Chem C 111:14469

20. Graciani J, Nambu A, Evans J, Rodríguez JA, Sanz JF (2008) J Am Chem Soc 130:12056

21. Parker SC, Grant AW, Bondzie VA, Campbell CT (1999) Surf Sci 441:1-10 
22. Minato T, Susaki T, Shiraki S, Kato HS, Kawai M, Aika KI (2004) Proceedings of the 22nd European Conference on Surface Science, Prague, vol 566-568 (Part 2), p 1012

23. Cruz N, Sanz JF, Rodríguez JA (2006) J Am Chem Soc 128:15600

24. Wörz AS, Heiz U, Cinquini F, Pacchioni G (2005) J Phys Chem B 109:18418

25. Liu Z, Cui ZL, Zhang K (2005) Mater Charact 54:123

26. Panero WR, Stixrude L, Ewing RC (2004) Phys Rev B 70(5):054110

27. Avellaneda RS (2010) Estudio e influencia del Y y otros modificadores superficiales en el comportamiento de catalizadores soportados en TiO2. Ph.D. thesis, Universidad de Sevilla, Sevilla, Spain

28. Kresse G, Hafner J (1996) Phys Rev B 47:558

29. Kresse G, Furthmüller J (1996) Comput Mater Sci 6:15

30. Kresse G, Furthmüller J (1996) Phys Rev B 54(16):11169

31. Blöchl PE (1994) Phys Rev B 50(24):17953

32. Kresse G, Joubert D (1999) Phys Rev B 59(3):1758

33. Perdew JP, Chevary JA, Vosko SH, Jackson KA, Pederson MR, Singh DJ, Fiolhais C (1992) Phys Rev B 46(11):6671

34. Harris J (1985) Phys Rev B 31(4):1770

35. Diebold U (2003) Surf Sci Rep 48(5-8):53

36. Lazzeri M, Vittadini A, Selloni A (2001) Phys Rev B 63(15):155409

37. Monkhorst HJ, Pack JD (1976) Phys Rev B 13(12):5188

38. Henkelman G, Arnaldsson A, Jónsson H (2006) Comput Mater Sci 36:354

39. Sanville E, Kenny SD, Smith R, Henkelman G (2007) J Comput Chem 28:899

40. Bader R (1990) Atoms in molecules: a quantum theory. Oxford University Press, Oxford

41. Malati MA, Wong WK (1984) Surf Technol 22:305

42. Shcherbakova LG, Mamsurova LG, Sukhanova GE (1979) Russ Chem Rev 48:423

43. Parks G (1965) Chem Rev 65:177

44. Radecka M, Zakrzewska K, Wierzbicka M, Gorzkowska A, Komornicki S (2003) Solid State Ionics 157(1-4):379 
45. Serpone N (2006) J Phys Chem B 110(48):24287

46. Carrettin S, Hao Y, Aguilar-Guerrero V, Gates BC, Trasobares S, Calvino JJ, Corma A (2007) Chem Eur J 13:27-7771

47. Centeno MA, Hidalgo MC, Domínguez MI, Navio JA, Odriozola JA (2008) Catal Lett 123:198

48. Thomas AG, Flavell WR, Kumarasinghe AR, Mallick AK, Tsoutsou D, Smith GC, Stockbauer R, Patel S, Grätzel M, Hengerer R (2003) Phys Rev B 67(3):035110

49. Gole JL, Prokes SM, Gelmbocki OJ (2008) J Phys Chem C 112:1782

50. Lin J, Yu JC (1998) J Photochem Photobiol 116:63 (112)

51. Fischer J, Hollomon J, Leschen J (1950) Ind Eng Chem 44:6-1324

52. Ganduglia-Pirovano MV, Hofmann A, Sauer J (2007) Surf Sci Rep 62:219

53. Oviedo J, San Miguel MA, Sanz JF (2004) J Chem Phys 121:7427

54. Vittadini A, Selloni A (2002) J Chem Phys 117:353

55. Graciani J, Álvarez LJ, Rodríguez JA, Sanz JF (2008) J Phys Chem C 112:2624

56. Graciani J, Ortega Y, Sanz JF (2009) Chem Mater 21:1431

57. Roldan A, Boronat M, Corma A, Illas Francesc (2010) J Phys Chem C 114:6511

58. Carrettin S, Hao Y, Aguilar-Guerrero V, Gates BC, Trasobares S, Calvino JJ, Corma A (2007) Chem Eur J 13:7771

59. Karvinen S (2003) Sol State Sci 5:811

60. Cavalheiro AA, Bruno JC, Saeki MJ, Valente JPS, Florentino AO (2008) J Mater Sci 43:602

61. Perdew JP, Levy M (1983) Phys Rev Lett 51:20-1884

62. Sham LJ, Schlüter M (1983) Phys Rev Lett 51:20-1888

63. Lany S, Zunger A (2008) Phys Rev B 78(23):235104

64. Campbell C, Parker S, Starr D (2002) Sience 298:811

65. Molina LM, Hammer B (2003) Phys Rev Lett 90:20-206102 


\section{Figure captions}

Figure 1. $3 \times 3$ supercell model of the anatase TiO2 (101) surface with $2 \mathrm{O}-\mathrm{Ti}-\mathrm{O}$ layers. The bottom layer is kept frozen and the top layer is fully optimized. Atoms colors: red $\mathrm{O}$, gray $\mathrm{Ti}$

Figure 2. CO conversion versus temperature for the studied catalysts

Figure 3. Relationship between the nominal and real (measured by XRF) yttrium content on the synthesized supports

Figure 4. UV-VIS spectra of the synthesized supports

Figure 5. Relationship between the catalytic activity $\left(\mathrm{T}_{50}\right)$ and the secondary band gap of the studied solids

Figure 6. XRD patterns of TiY11 and TiY13 supports calcined at $950{ }^{\circ} \mathrm{C}(\mathrm{A}=$ anatase; $\mathrm{R}=$ rutile; $\mathrm{P}=$ stoichiometric pyrochlore, Ti2Y2O7, $\mathrm{Y} / \mathrm{Ti}=$ non-stoichiometric pyrochlore, TiYO2.085

Figure 7. Top view of a $3 \times 3$ supercell model of the anatase TiO2 (101) surface with six $\mathrm{Y} / \mathrm{Ti}$ substitutions and three $\mathrm{O}$ vacancies (denoted by crossed circles). Atoms colors: red $\mathrm{O}$, gray $\mathrm{Ti}$, and brown $\mathrm{Y}$. The $3 \times 3$ supercell is duplicated in this figure

Figure 8. Computed band structure of undoped (top) and Y-doped (6\%-middle and $16 \%$ - bottom) models of the (101) anatase surface. The two most important indirect transitions of the material are also show

Figure 9. Variation of the band gap of the material with the yttrium content in experimental synthesized supports (black) and theoretical computed band gaps (red) for the three surface models developed

Figure 10. Total density of states (black) and gold projected density of states (red) for Au4 cluster deposited over hydroxylated model of undoped (top) and Y-doped (bottom) anatase (101) surface 
Table 1

Table 1

Chemical compositions, IEP, BET surface area, and gold particle size of the studied catalysts

\begin{tabular}{|c|c|c|c|c|c|}
\hline \multirow{2}{*}{ Solid } & \multicolumn{2}{|c|}{$100 \mathrm{Y} /(\mathbf{T i}+\mathbf{Y})$} & \multirow{2}{*}{ IEP } & \multirow{2}{*}{ S BET with Au $\left(\mathrm{m}^{2} \mathrm{~g}^{-1}\right)$} & \multirow{2}{*}{ Dp (Au) (nm) } \\
\hline & Nominal & Measured & & & \\
\hline TiY0 & 0 & 0 & 4.73 & 37 & 11 \\
\hline TiY6 & 7 & 6 & 4.05 & 150 & 9 \\
\hline TiY11 & 20 & 11 & 3.86 & 154 & - \\
\hline
\end{tabular}

We were unable to size the TiY11 sample 
Table 2

Table 2

Band gap values for the catalytic supports

\begin{tabular}{|l|l|l|}
\hline Support & \multicolumn{2}{l|}{ Band gap (eV) } \\
\cline { 3 - 3 } & Secondary & Main \\
\hline TiY0 & 1.94 & 3.13 \\
\hline TiY6 & 2.27 & 3.05 \\
\hline TiY11 & 2.34 & 3.08 \\
\hline
\end{tabular}




\section{Table 3}

Table 3

Computed relative energies $(\mathrm{eV})$ corresponding to $3 \times 3$ models of anatase (101) surface with six $\mathrm{Y} / \mathrm{Ti}$ substitutions and three $\mathrm{O}$ vacancies

\begin{tabular}{|l|l|l|l|}
\hline Model & E/eV & Model & E/eV \\
\hline $50 \% \mathrm{Ti}(\mathrm{a})$ & 0.00 & $100 \% \mathrm{Ti}(\mathrm{d})$ & 1.84 \\
\hline $50 \% \mathrm{Ti}$ (b) & 0.92 & $50 \% \mathrm{Ti}$ (c) & 2.08 \\
\hline $100 \% \mathrm{Ti}(\mathrm{a})$ & 1.45 & $50 \% \mathrm{Ti}(\mathrm{d})$ & 2.34 \\
\hline $100 \% \mathrm{Ti}$ (b) & 1.45 & $100 \% \mathrm{Ti}(\mathrm{e})$ & 2.70 \\
\hline $100 \% \mathrm{Ti}(\mathrm{c})$ & 1.82 & $100 \% \mathrm{Ti}(\mathrm{f})$ & 2.93 \\
\hline
\end{tabular}

Each configuration is denoted by the percent of surface Ti atoms substituted and a label to distinguish them 
Table 4

Table 4

Computed adsorption energies (eV) for single gold atoms and $\mathrm{Au}_{4}$ nanoclusters on surface models of undoped and Y-doped anatase (101) surfaces

\begin{tabular}{|l|l|l|}
\hline \multicolumn{1}{|l|}{ Model } & \multicolumn{1}{l|}{ E/eV } \\
\cline { 2 - 3 } & Au & Au4 \\
\hline $\mathrm{TiO}_{2}$ & -0.46 & -1.10 \\
\hline Hydrated $\mathrm{TiO}_{2}$ & -0.54 & -1.36 \\
\hline Y-doped $\mathrm{TiO}_{2}$ & -0.81 & -2.39 \\
\hline Hydrated $\mathrm{Y}$-doped $\mathrm{TiO}_{2}{ }^{\mathrm{a}}$ & -0.47 & -1.96 \\
\hline Hydrated Y-doped $\mathrm{TiO}_{2}{ }^{\mathrm{b}}$ & -0.42 & -2.01 \\
\hline${ }^{2}$ One Au atom sits at the O-vacancy \\
b An OH is occupying the O-vacancy
\end{tabular}




\section{Table 5}

Table 5

Bader charges for $\mathrm{Au}_{\mathrm{n}}(\mathrm{n}=1-4)$ clusters interacting with surface models of undoped and Y-doped anatase (101) surfaces

\begin{tabular}{|l|l|l|l|l|}
\hline Model & Au & Aus & Aus & Au4 \\
\hline $\mathrm{TiO}_{2}$ & +0.46 & +0.02 & +0.56 & +0.17 \\
\hline Hydrated $\mathrm{TiO}_{2}$ & +0.02 & -0.01 & +0.55 & +0.03 \\
\hline Y-doped $\mathrm{TiO}_{2}$ & -0.14 & -0.09 & -0.05 & -0.14 \\
\hline Hydrated $\mathrm{Y}_{\text {-doped }} \mathrm{TiO}_{2}{ }_{2}^{\mathrm{a}}$ & -0.05 & -0.14 & -0.10 & -0.18 \\
\hline Hydrated Y-doped $\mathrm{TiO}_{2}{ }_{2}^{\mathrm{b}}$ & -0.01 & -0.08 & -0.08 & -0.08 \\
\hline
\end{tabular}

${ }^{a}$ One gold atoms sits at the O-vacancy

${ }^{\mathrm{b}} \mathrm{An} \mathrm{OH}$ is occupying the $\mathrm{O}$-vacancy 
Figure 1

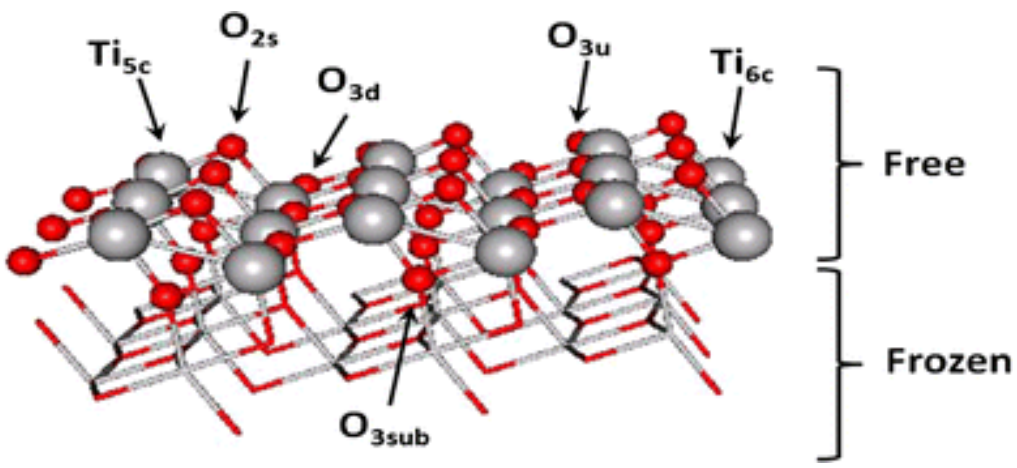


Figure 2

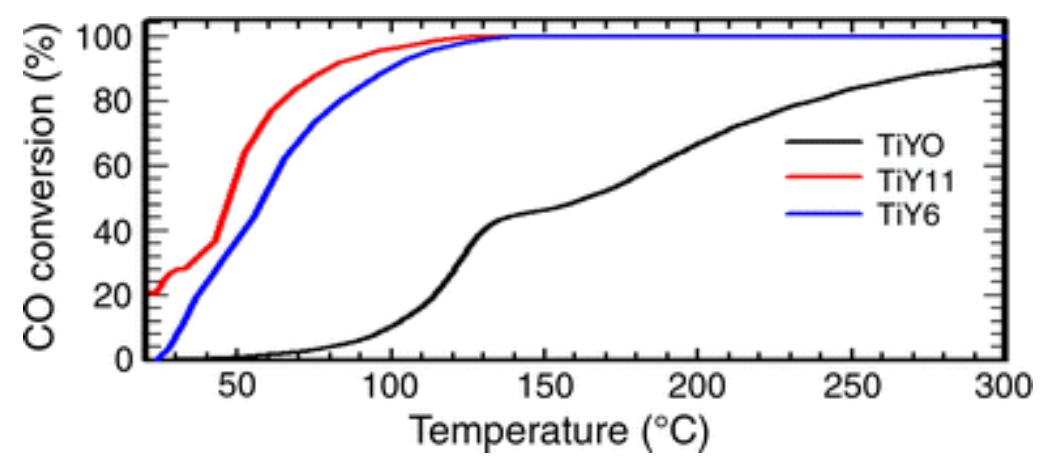


Figure 3

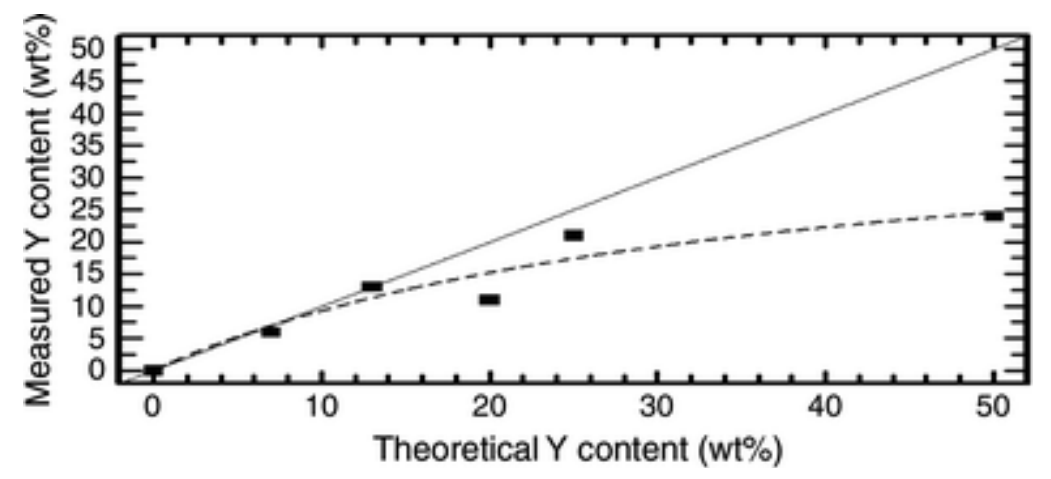


Figure 4

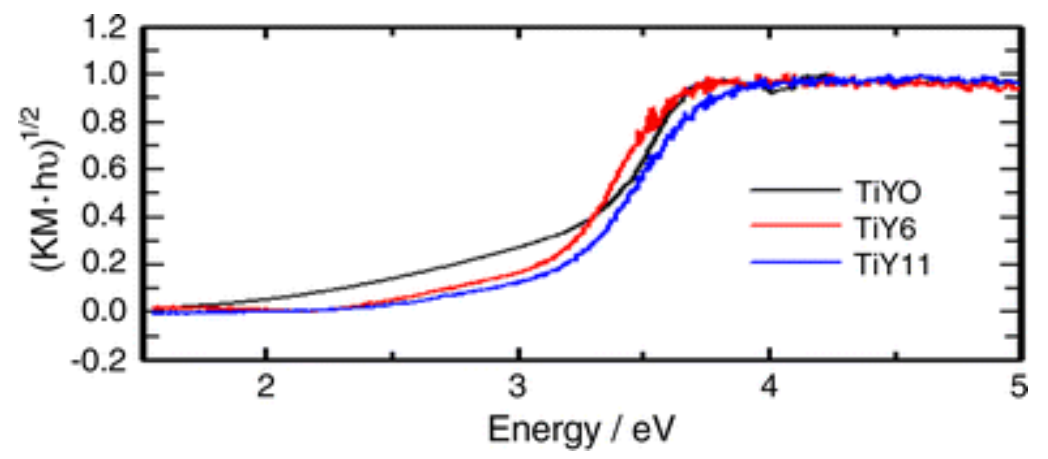


Figure 5

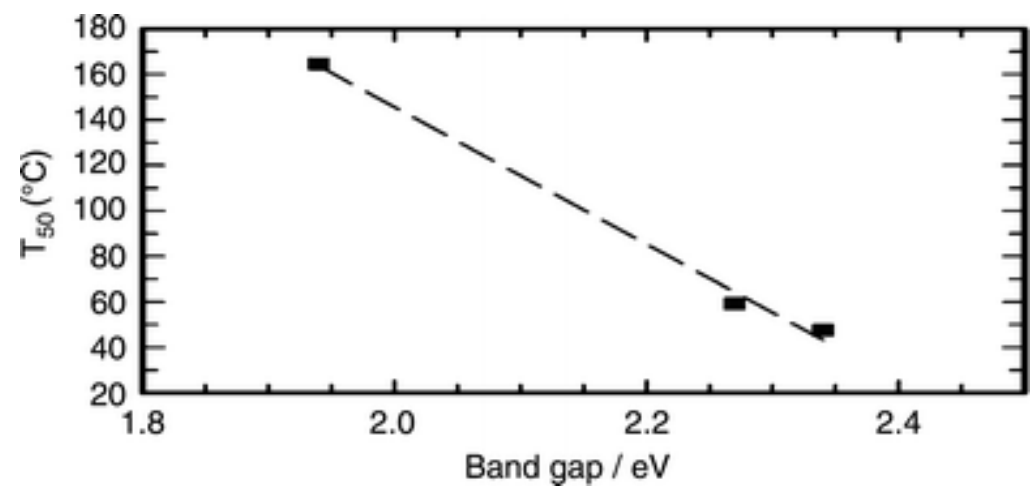


Figure 6

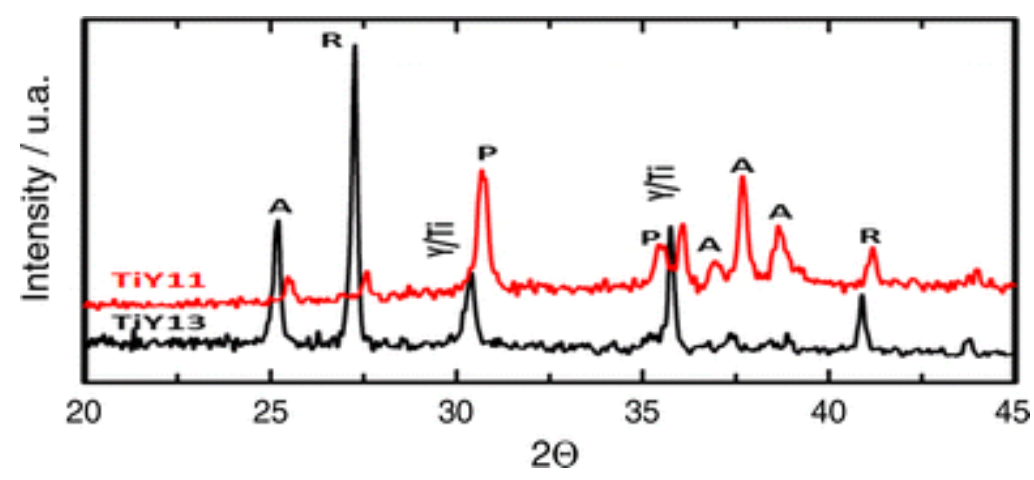


Figure 7

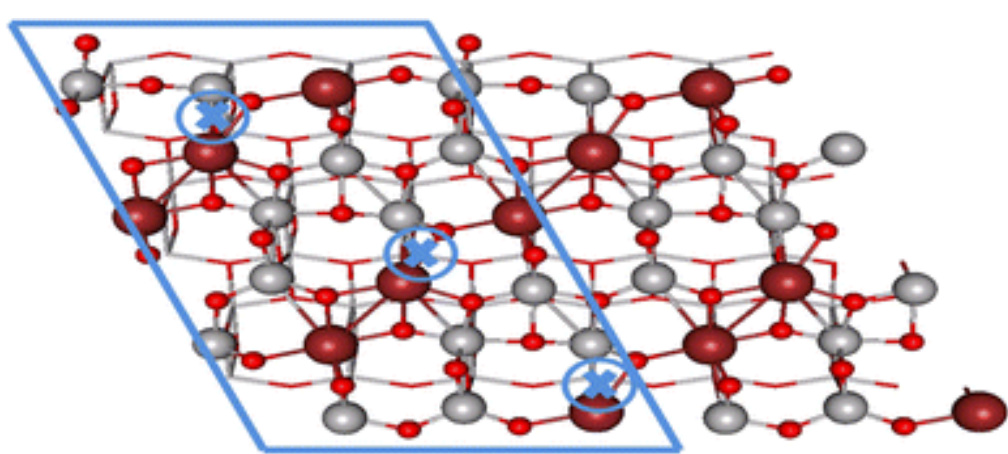


Figure 8

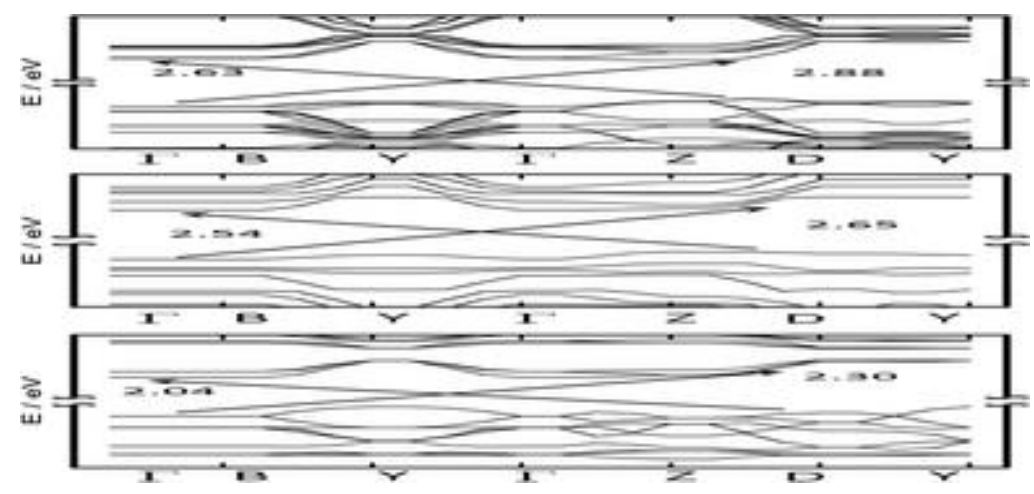


Figure 9

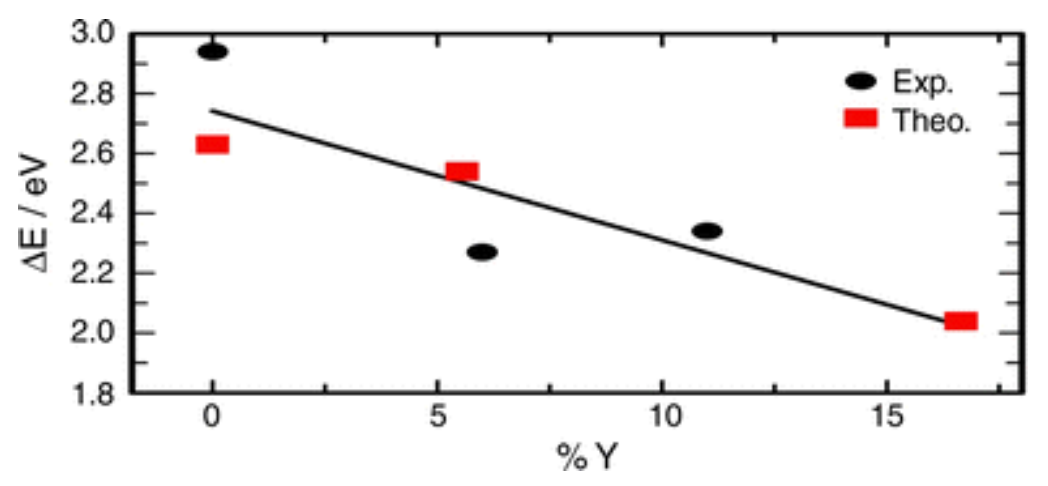


Figure 10

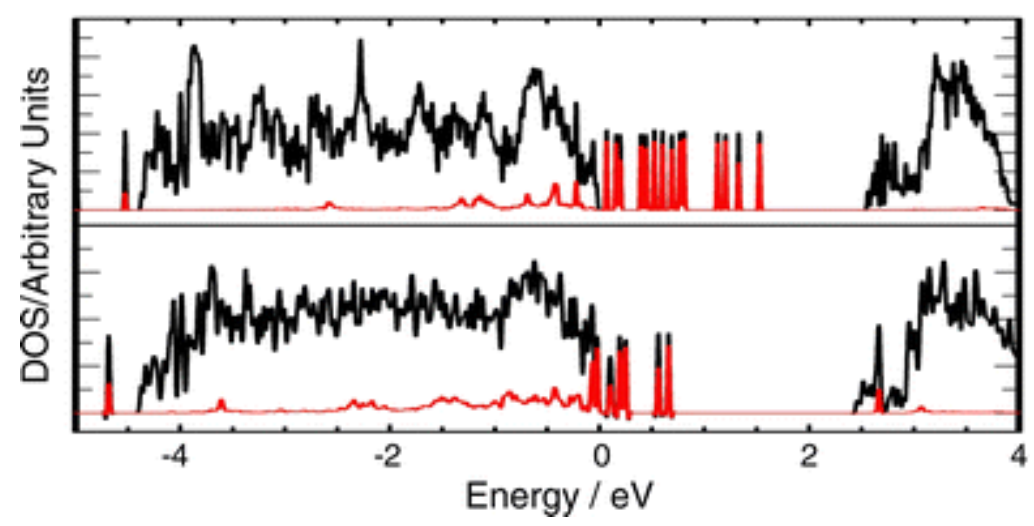

